\title{
Looking forward to the global scholastic network of Journal of Exercise Rehabilitation
}

\author{
Yong-Seok Jee (iD https://orcid.org/0000-0001-6797-0843
}

As Korea approaches the status of an aged society and the prevalence of illnesses steadily rises, exercise rehabilitation is needed now more than ever. The Korean Society of Exercise Rehabilitation (KSER) publishes the Journal of Exercise Rehabilitation (JER) with the aim of improving the academic field of theoretical and practical studies by identifying problems and working toward finding viable solutions. For the past 10 years, JER has published influential research papers as KSER continues to support and work together with exercise rehabilitation specialists in promoting a healthier society marked by physical, mental, and social well-being.

The purpose of JER is to share significant findings in therapeutic mechanisms and the effects of exercise rehabilitation on various diseases. In other words, JER aims to exist as a medium for scientifically verifying the efficacy of physical activity or exercise. The scope of fields covered in JER consists of welfare, psychology, pedagogy, clinical application, and mechanisms associated with exercise rehabilitation. Furthermore, JER has strategically included a range of integrative studies based on the principles and applications of exercise rehabilitation with a particular emphasis on behavioral therapy. As an open access international journal, JER permits unrestricted noncommercial use, distribution, and reproduction in any medium, provided the original work is properly cited. All international journals comply with international academic journal standards and accept manuscript submissions by researchers from all over the world. In addition to supporting scholars who publish exceptional articles in international journals, fostering academic journals that advance academic disciplines in these fields is crucial for raising national competitiveness. In order to become an international journal, JER published all articles in English since April 2013 and was listed in PubMed and PubMed
Central in November 2013. By November 2017, JER was listed in Scopus and was also accepted in the Emerging Sources Citation Index (ESCI) in April 2018 (Kim, 2018). JER is now waiting to be listed in the Social Science Citation Index (SSCI).

JER's mission is to further investigate and elucidate various aspects of exercise to promote prevention and rehabilitation for existing and new complications. Moreover, continuously updating the contents of the journal and expanding the global scholastic network are necessary toward becoming a leader in the field of exercise rehabilitation. Therefore, it is my hope for JER to become a scholarly journal that integrates academic expertise in each field and contributes to the promotion of health. I commend JER for all of their accomplishments through hard work and perseverance as I look forward to even greater milestones in the near future.

\section{CONFLICT OF INTEREST}

No potential conflict of interest relevant to this article was reported.

\section{REFERENCE}

Kim CJ. Internationalization strategy of Journal of Exercise Rehabilitation. J Exerc Rehabil 2018;14:157.

Associate Editor of the Journal of Exercise Rehabilitation Research Institute of Sports and Industry Science, Hanseo University, 46 Hanseo 1-ro, Haemi-myeon, Seosan 31962, Korea E-mail: jeeys@hanseo.ac.kr 